\title{
Small GTPase RhoD suppresses cell migration and cytokinesis
}

\author{
Keisuke Tsubakimoto ${ }^{1}$, Ken Matsumoto ${ }^{1}$, Hiroshi Abe ${ }^{1}$, Junichiro Ishii ${ }^{1}$, Mutsuki Amano ${ }^{2}$, \\ Kozo Kaibuchi ${ }^{2}$ and Takeshi Endo*,1
}

${ }^{1}$ Department of Biology, Faculty of Science, Chiba University, Yayoicho, Inageku, Chiba, Chiba 263-8522, Japan; ${ }^{2}$ Division of Signal Transduction, Nara Institute of Science and Technology, Ikoma, Nara 630-0101, Japan

\begin{abstract}
Rho family small GTPases regulate organization of the actin cytoskeleton. Among them, RhoA plays essential roles in the formation of the actin stress fibers, the associated focal adhesions, and the contractile rings necessary for cytokinesis. Recently, RhoD, a novel member of Rho family has been identified. The amino acid sequences of its effector domain is distinct from those of the other Rho family proteins, suggesting its unique cellular functions. Introduction of the constitutively active form of $\operatorname{RhoD}^{\mathrm{G} 26 \mathrm{~V}}$ into fibroblasts by microinjection or transfection resulted in disassembly of the actin stress fibers and the focal adhesions, whereas the dominant negative form of $\mathrm{RhoD}^{\mathrm{T} 31 \mathrm{~K}}$ did not affect these structures. The degree of cell migration assessed by the phagokinetic tracks on a substrate covered with gold particles was diminished by the expression of $R \mathrm{HoD}^{\mathrm{G} 26 \mathrm{~V}}$

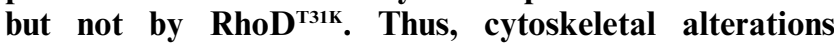
including the loss of stress fibers and focal adhesions by RhoD seems to lead to the retardation of cell migration. Transfection of RhoD ${ }^{\mathrm{G} 26 \mathrm{~V}}$ cDNA into cultured cells also induced multinucleation. Moreover, RhoD ${ }^{\mathrm{G} 26 \mathrm{~V}}$ microinjected into fertilized eggs and embryos of Xenopus laevis caused cleavage arrest only in the injected cells, and the uncleaved cells contained multiple nuclei. These results imply that RhoD does not affect nuclear division but can interfere with cytokinesis presumably by preventing the formation of the actin-based contractile ring. Enhancement of the stress fibers by RhoA or RhoA-activating lysophosphatidic acid was reversed by the transfection of RhoD cDNA. Accordingly, the cellular functions of RhoD are likely to be antagonistic to those of RhoA.
\end{abstract}

Keywords: small GTPase; Rho family; actin cytoskeleton; cell motility; cytokinesis

\section{Introduction}

The actin cytoskeleton mediates various cellular functions including cell motility, cell adhesion, and cell division. Members of the mammalian Rho family small GTPases have emerged as key regulators that link cell surface receptors to the organization of the actin cytoskeleton. The family comprises RhoA, RhoB, RhoC, Rac1, Rac2, Cdc42, Tc10, RhoG, RhoE, and recently identified RhoD (Narumiya, 1996; Murphy et

*Correspondence: $\mathrm{T}$ Endo

Received 23 June 1998; revised 25 November 1998; accepted 11 December 1998 al., 1996; Van Aelst and D'Souza-Schorey, 1997). The functions of RhoA, Rac1, and $\mathrm{Cdc} 42$ and their target effector proteins have been intensively examined. In fibroblasts, activation of RhoA by the extracellular ligand lysophosphatidic acid (LPA) leads to the assembly of contractile actin stress fibers and associated focal adhesions (Ridley and Hall, 1992). Racl activated by platelet-derived growth factor or insulin induces the assembly of an actin filament meshwork to generate membrane ruffles (lamellipodia) and specific focal complexes (Ridley et al., 1992; Nishiyama et al., 1994; Nobes and Hall, 1995). On the other hand, Cdc42 activated by bradykinin is responsible for the formation of actin filamentcontaining microspikes (filopodia) and associated focal complexes (Kozma et al., 1995; Nobes and Hall, 1995). In addition, Cdc42 can activate Rac1, hence extension of filopodia is accompanied by concerted lamellipodial spreading (Kozma et al., 1995; Nobes and Hall, 1995). Sequentially Racl can activate RhoA to form stress fibers, although this is a weak and delayed response in fibroblasts (Ridley et al., 1992; Hall, 1998).

Microinjection of Clostridium botulinum C3 ADPribosyltransferase (C3 exoenzyme), which inactivates RhoA by ADP-ribosylating its effector domain, or Rho guanine nucleotide dissociation inhibitor (Rho GDI) into Swiss 3T3 fibroblasts causes inhibition of cell migration (Takaishi et al., 1993). Hepatocyte growth factor $(\mathrm{HGF})$ or 12-O-tetradecanoylphorbol-13-acetate (TPA) induces cell migration of a mouse keratinocyte cell line. The migration is also suppressed by microinjection of C3 exoenzyme or Rho GDI (Takaishi et al., 1994). These findings suggest that RhoA mediates migration of these cells.

When C3 exoenzyme or Rho GDI is injected into Xenopus embryos (Kishi et al., 1993; Drechsel et al., 1997) or sand dollar eggs (Mabuchi et al., 1993), actin/ myosin-based contractile ring formation is inhibited. In addition, if C3 exoenzyme is injected during cleavage, it causes regression of the cleavage furrow (Mabuchi et al., 1993). Inhibition of RhoA by these proteins results in the interference with cytoplasmic cleavage but not with nuclear division and consequently multinucleation is induced (Kishi et al., 1993; Mabuchi et al., 1993). Accordingly, RhoA is required for progression of cleavage through the formation of contractile ring.

RhoD has been cloned by the strategy based on the polymerase chain reaction (Murphy et al., 1996; Matsumoto et al., 1997). The amino acid sequence of its effector domain is distinct from those of the other members of the Rho family, suggesting its unique functions among the family. When wild-type or constitutively activated RhoD is transiently expressed in various types of cultured cells by the $\mathrm{T} 7$ vaccinia 
virus system, it induces rearrangements of actin cytoskeleton (Murphy et al., 1996). The actin stress fibers disappear, and instead actin-containing long thin processes are formed at the cell periphery. In addition, any focal complexes containing vinculin or paxillin are disassembled in the cells. RhoD also interferes with the formation of large endosomes by the homotypic fusion between the early endosomes in response to the constitutively active form of Rab5 (Murphy et al., 1996). This is likely to be primarily due to an inhibition of intracellular motility of the early endosomes through disrupting cytoskeletal filaments.

In the present study, we examined the effects of RhoD on the cell migration and mitosis. The degree of cell migration was diminished by the expression of activated RhoD. Cytoskeletal changes including the loss of stress fibers and focal adhesions by RhoD may lead to the inhibition of cell migration. Transfection of the activated RhoD cDNA into cultured cells also induced multinucleation. Microinjection of the activated RhoD protein into Xenopus eggs and embryos gave rise to cleavage arrest and generated the uncleaved cells containing multiple nuclei. Thus, RhoD does not affect mitosis but can impede cytokinesis possibly by preventing the formation of the contractile ring. Furthermore, enhancement of the stress fibers by RhoA or LPA was reversed by the transfection of RhoD cDNA. These results suggest that RhoD antagonizes the effects of RhoA on the actin cytoskeleton.

\section{Results}

\section{Structural properties of RhoD}

We have cloned a cDNA encoding RhoD by screening a cDNA library of the mouse skeletal muscle C2 myotubes with a product of the $3^{\prime}$ rapid amplification of cDNA ends (3' RACE) (Matsumoto et al., 1997) based on the polymerase chain reaction. This cDNA includes the entire coding region as well as the $5^{\prime}$ and $3^{\prime}$ untranslated regions (DDBJ/EMBL/GenBank Data Bank accession number D89821). The predicted amino acid sequence of this cDNA is identical to that reported by Murphy et al. (1996). Comparison of the entire amino acid sequence with those of the other members of the Rho family indicates that RhoD is distinct from the other members over the whole sequence (data not shown). This is corroborated by the evolutional relationship that RhoD diverged from the other Rho family proteins at an early stage of evolution (Matsumoto et al., 1997). RhoD is distinct from the other Rho family members as many as seven amino acids with respect to the nature of their side chains within the core effector domain and the putative extended effector domain (Self et al., 1993) (Figure 1). This sequence divergence of RhoD suggests that it interacts with specific target proteins and that consequently it exerts unique cellular functions.

\section{Destruction of stress fibers and focal adhesions by RhoD}

To examine the effects of RhoD in fibroblasts, the bacterially expressed recombinant proteins were microinjected into serum-starved subconfluent Swiss 3T3 cells. These quiescent cells still contained many actin stress fibers although the stress fibers were thinner than those in proliferating cells (Kozma et al., 1995). Fluorescein-conjugated dextran was coinjected with the proteins to identify injected cells. When the cells were microinjected with the constitutively active form of $\mathrm{RhoD}^{\mathrm{G} 26 \mathrm{~V}}$, most stress fibers disappeared within $30 \mathrm{~min}$, as detected by rhodamine-phalloidin staining (Figure 2a). This result is consistent with the previous report (Murphy et al., 1996), although thin processes containing actin filaments were not definitely formed in the injected cells compared with uninjected cells under these conditions. Injection of the dominant negative RhoD $^{\mathrm{T} 31 \mathrm{~K}}$ did not cause appreciable cytoskeletal changes (Figure 2b).

cDNAs encoding the constitutively active and the dominant negative forms of RhoD, which were fused with Myc-epitope tag at their N-termini, were expressed by transient transfection in proliferating $\mathrm{C} 3 \mathrm{H} / 10 \mathrm{~T} 1 / 2$ fibroblasts. We used this cell line for transfection instead of Swiss 3T3 cells owing to much higher transfection efficiency. The cells were doubly stained with the monoclonal antibody (mAb) Mycl9E10 recognizing the Myc-tag and rhodamine-phalloidin. The RhoD ${ }^{\mathrm{G} 26 \mathrm{~V}}$-expressing cells often exhibited disappearance of the stress fibers and instead diffused phalloidin staining throughout the cytoplasm within $18 \mathrm{~h}$ after the transfection (Figure 2c). This diffused phalloidin staining appears to represent disassembled or further fragmented actin filaments. Double staining with Myc1-9E10 and anti-vinculin antibody showed that the focal adhesions also became scarcely detectable in most of the $\mathrm{RhoD}^{\mathrm{G} 26 \mathrm{~V}}$-expressing cells (Figure 2e). Thin processes were not always evident in the expressing cells under these conditions either. Whole appearance, the actin cytoskeleton, and the focal adhesions of the $\mathrm{RhoD}^{\mathrm{T} 31 \mathrm{~K}}$-expressing cells were indistinguishable from those of the untransfected cells (Figure 2d and f).

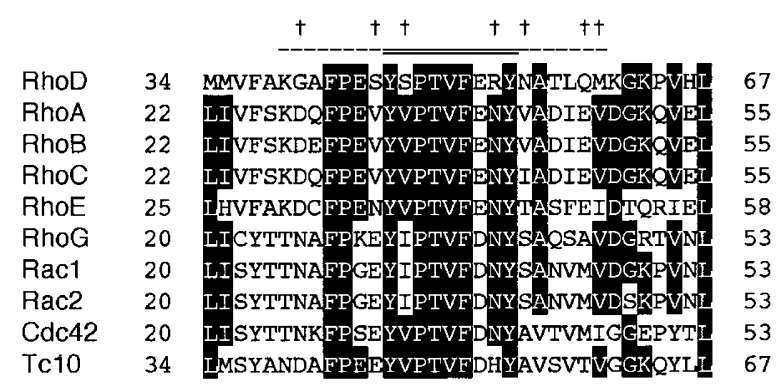

Figure 1 Comparison of the amino acid sequence of RhoD with those of known Rho family members around the core and the extended effector domains. The origins of known Rho family proteins are human RhoA (Yeramian et al., 1987), mouse RhoB (Nakamura et al., 1996), mouse RhoC (Segade et al., 1995), human RhoE (Foster et al., 1996), human RhoG (Vincent et al., 1992), mouse Rac1 (Moll et al., 1991), mouse Rac2 (Shirsat et al., 1990), mouse Cdc42 (Marks and Kwiatkowski, 1996), and human Tc10 (Drivas et al., 1990). Amino acids at positions of $>50 \%$ identity are shown in white on black. Double overlines and dashed overlines denote the core and the putative extended effector domains, respectively. Amino acids in RhoD distinct from those in the other Rho family proteins in the core and extended effector domains are pointed out by daggers 

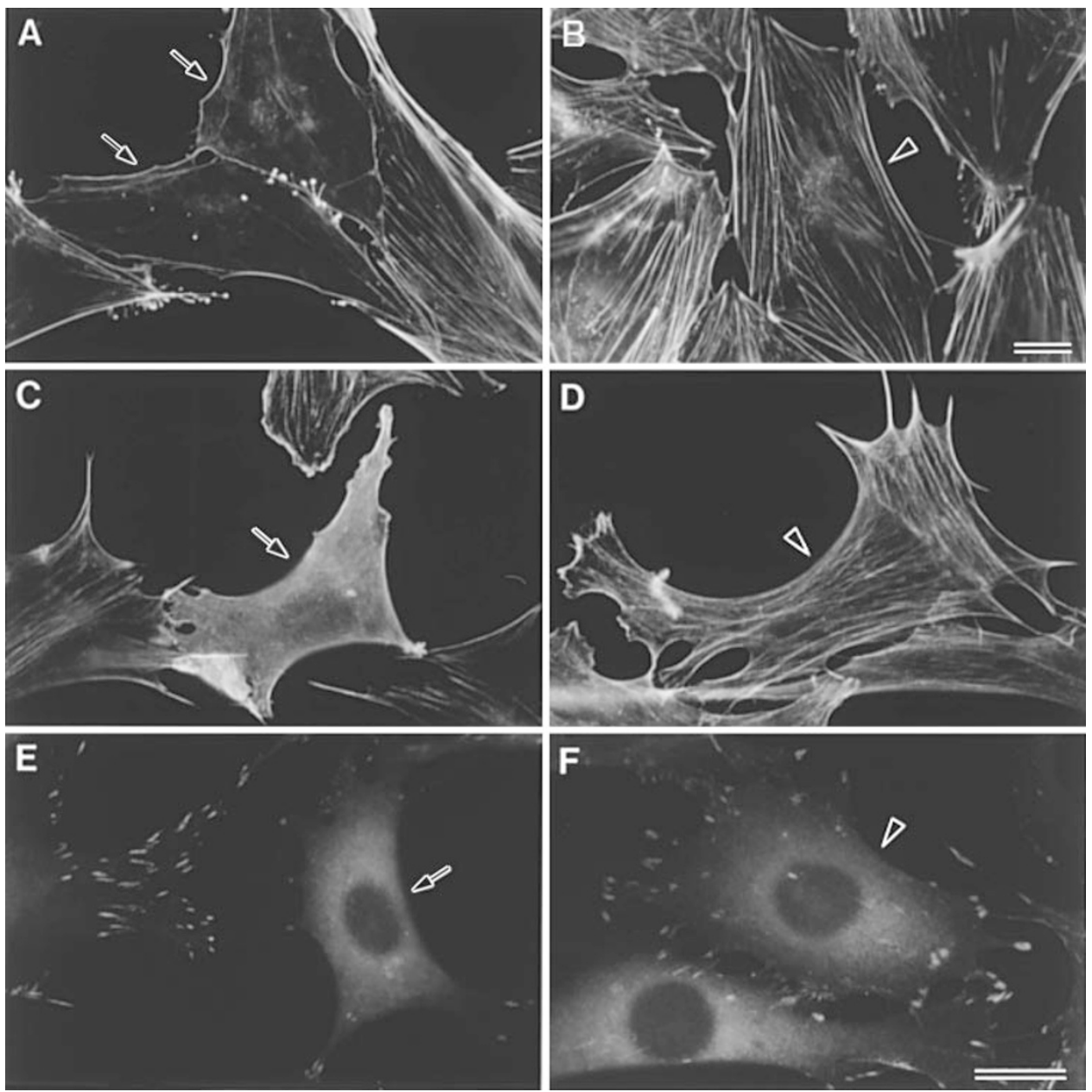

Figure 2 Destruction of the stress fibers and the focal adhesions by the activated RhoD introduced by microinjection and transfection. (a and b) Serum-starved subconfluent Swiss 3T3 cells microinjected with the recombinant constitutively active $\mathrm{RhoD}^{\mathrm{G} 26 \mathrm{~V}}$ (a) or dominant negative $\mathrm{RhoD}^{\mathrm{T} 31 \mathrm{~K}}$ (b) protein, $30 \mathrm{~min}$ after the injection. (c-f) Transfected 10T1/2 cells expressing Myc-tagged RhoD ${ }^{\mathrm{G} 26 \mathrm{~V}}$ (c and $\mathbf{e}$ ) or $\mathrm{RhoD}^{\mathrm{T} 31 \mathrm{~K}}$ (d and $\mathbf{f}$ ), $24 \mathrm{~h}$ after the transfection in the growth medium. Cells were stained with rhodamine-phalloidin to detect actin filaments $(\mathbf{a}-\mathbf{d})$ or with anti-vinculin antibody to detect focal adhesions (e and $\mathbf{f})$. Arrows indicate the $\mathrm{RhoD}{ }^{\mathrm{G} 26 \mathrm{~V}}$-injected cells (a) or the $\mathrm{Myc}-\mathrm{RhoD}^{\mathrm{G} 26 \mathrm{~V}}$-expressing cells (c and $\mathbf{e}$ ), in which the stress fibers and focal adhesions disappeared. Arrowheads point to the $\mathrm{RhoD}^{\mathrm{T} 31 \mathrm{~K}}$-injected cells $(\mathbf{b})$ or the $\mathrm{Myc}-\mathrm{RhoD}^{\mathrm{T} 31 \mathrm{~K}}$-expressing cells $(\mathbf{d}$ and $\mathbf{f})$, in which the stress fibers and focal adhesions remained. Injected cells were detected by coinjection of fluorescein-dextran. Transfected cells were detected by immunofluorescent staining with the mAb Myc1-9E10. Scale bars, $20 \mu \mathrm{m}$

\section{Suppression of cell migration by RhoD}

Since it has been suggested that actin-associated structures are involved in cell migration (Lauffenburger and Horwitz, 1996; Mitchison and Cramer, 1996), destruction of the stress fibers and focal adhesions by RhoD prompted us to examine the effect of the protein on cell migration. The degree of cell migration was assayed by phagokinetic tracks of $10 \mathrm{~T} 1 / 2$ cells on gold particle-coated glass coverslips (Albrecht-Buehler, 1977). The cells were transfected with the Myc-tagged cDNA of $\mathrm{RhoD}^{\mathrm{G} 26 \mathrm{~V}}$ or $\mathrm{RhoD}^{\mathrm{T} 31 \mathrm{~K}}$ and replated on the particle-coated coverslips. The tracks free of the particles generated by phagocytotic ingestion or attachment of the particles on the cell surface correspond to migration trails. The degree of migration was markedly retarded in most of the RhoD ${ }^{\mathrm{G} 26 \mathrm{~V}}$ expressing cells compared with untransfected cells (Figure $3 \mathrm{a}-\mathrm{c}$ ). On the other hand, RhoD ${ }^{\mathrm{T} 31 \mathrm{~K}}$-expressing cells migrated to the extent comparable to untransfected cells (Figure $3 \mathrm{~d}$ and e). In fact, the area of the tracks that the $\mathrm{RhoD}^{\mathrm{G} 26 \mathrm{~V}}$-expressing cells migrated $\left(4.8 \times 10^{3} \mu \mathrm{m}^{2}\right)$ was about one third and one fourth of what the untransfected and $\mathrm{RhoD}^{\mathrm{T} 31 \mathrm{~K}_{-}}$ expressing cells formed $\left(13.3 \times 10^{3} \mu \mathrm{m}^{2}\right.$ and $20.0 \times 10^{3} \mu \mathrm{m}^{2}$, respectively) (Table 1 ). These results evidently indicate that migration ability of the fibroblasts is suppressed by the forced expression of the activated RhoD.

\section{Induction of multinucleation in cultured cells by RhoD}

When Myc- RhoD ${ }^{\mathrm{G} 26 \mathrm{~V}}$ was expressed by transfection in Balb/3T3 and 10T1/2 fibroblasts and N1E-115 neuroblastoma cells, the cells with two to four nuclei became evident by $24 \mathrm{~h}$ after the transfection (Figure 4). The cytoplasm of such multinucleated cells tended to be larger than that of mononucleated cells. In Balb/3T3 cells, such multinucleated cells were $\sim 10 \%$ of the $\mathrm{RhoD}^{\mathrm{G} 26 \mathrm{~V}}$-expressing cells at this time (Table 2). On the other hand, essentially all of the untransfected cells and the cells transfected with the vacant Myc-tagging vector pCMVmyc contained single nuclei (Table 2). The ratio of multinucleated cells elevated up to $\sim 20 \%$ 

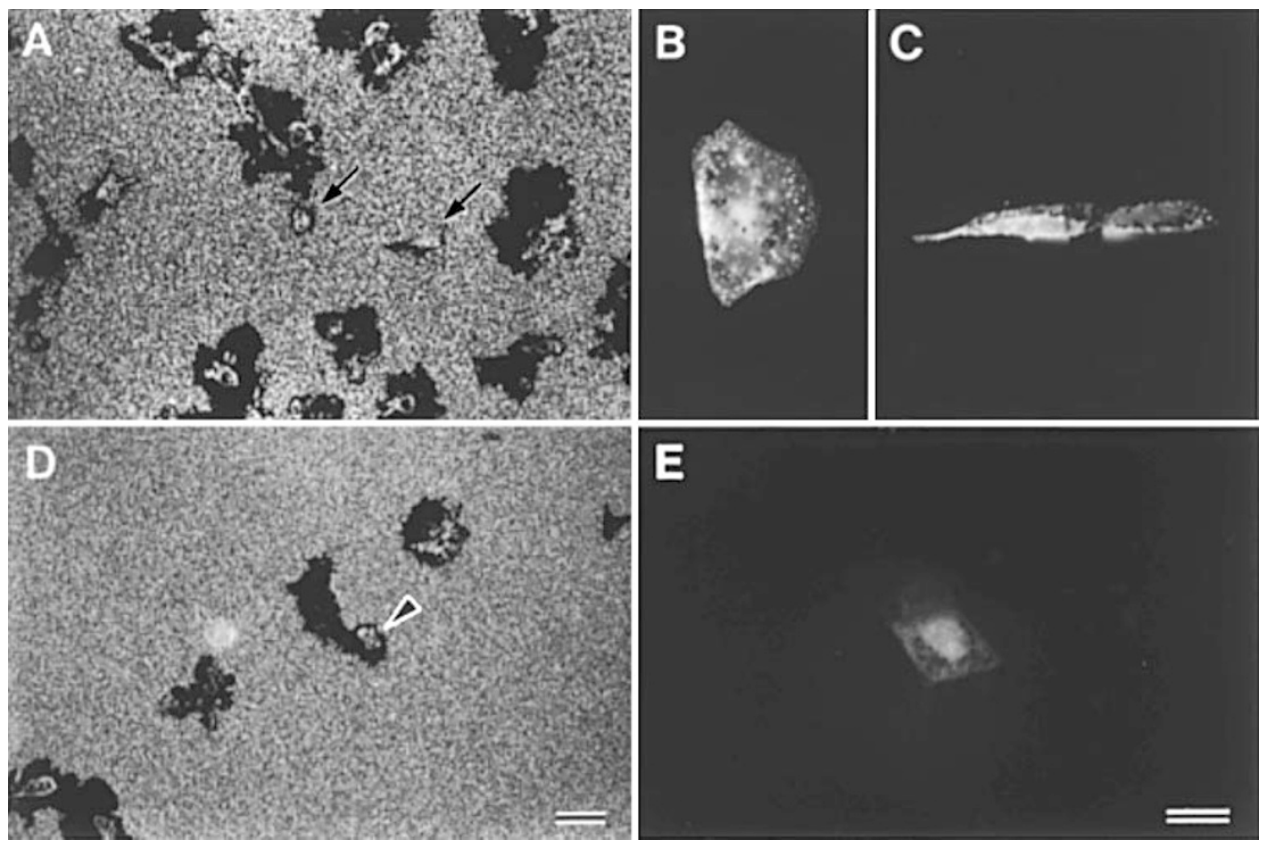

Figure 3 Phagokinetic tracks of $10 \mathrm{~T} 1 / 2$ cells expressing $\mathrm{RhoD}^{\mathrm{G} 26 \mathrm{~V}}$ and $\mathrm{RhoD}^{\mathrm{T} 31 \mathrm{~K}}$. (a-c) Phagokinetic tracks of Myc-RhoD ${ }^{\mathrm{G} 26 \mathrm{~V}}$ expressing cells. The tracks were examined by dark field microscopy (a). Arrows indicate the expressing cells, which were detected by immunofluorescent staining with Myc1-9E10 (b and c). (d and e) Phagokinetic tracks of Myc-RhoD ${ }^{\mathrm{T} 31 \mathrm{~K}}$-expressing cells examined by dark field microscopy (d). An arrowhead points to the expressing cell detected by the immunofluorescent staining with Mycl9 E10 (e). The transfected cells were replated on gold particle-coated coverslips $6 \mathrm{~h}$ after the transfection and fixed $18 \mathrm{~h}$ after the replating. Scale bars, $100 \mu \mathrm{m}$ (a and d) and $20 \mu \mathrm{m}(\mathbf{b}, \mathbf{c}$ and e)

Table 1 Retardation of cell migration by the activated RhoD estimated by phagokinetic tracks

\begin{tabular}{lc}
\hline Transfected $c D N A$ & Area of phagokinetic tracks $\left(\times 10^{3} \mu \mathrm{m}^{2}\right)$ \\
\hline None & $13.3 \pm 5.3$ \\
RhoD $^{\mathrm{G} 26 \mathrm{~V}}$ & $4.8 \pm 3.9$ \\
RhoD $^{\mathrm{T} 31 \mathrm{~K}}$ & $20.0 \pm 8.3$ \\
\hline
\end{tabular}

The phagokinetic tracks of 10T1/2 cells transfected with Myc-tagged $\mathrm{RhoD}^{\mathrm{G} 26 \mathrm{~V}}$ or RhoD ${ }^{\mathrm{T} 31 \mathrm{~K}}$ cDNA were recorded as micrographs and traced on graph paper. The area of the tracks $(n=12$ for each transfection experiment) was calculated and expressed as mean \pm s.d.

by $48 \mathrm{~h}$, but most of them contained two nuclei and few cells contained more than four nuclei (data not shown). Although a few per cent of $10 \mathrm{~T} 1 / 2$ and N1E115 cells already contained two nuclei prior to transfection, the percentage of multinucleated cells elevated after the transfection (Table 2).

Forced expression of a constitutively active mutant of $\mathrm{Cdc} 42^{\mathrm{G} 12 \mathrm{~V}}$ in human HeLa-derived cells has been shown to induce multinucleation and enlargement of the cytoplasm (Dutartre et al., 1996). We also transfected $\mathrm{Myc}-\mathrm{Cdc} 42^{\mathrm{G} 12 \mathrm{v}}$ cDNA to $\mathrm{Balb} / 3 \mathrm{~T} 3$, $10 \mathrm{~T} 1 / 2$, and N1E-115 cells. The cells became multinucleated similarly to those transfected with $\mathrm{Myc}-$ RhoD ${ }^{\mathrm{G} 26 \mathrm{~V}}$ cDNA. The ratio of the multinucleated cells was also $\sim 10 \%$ in the Balb/3T3 cells expressing $\mathrm{Cdc} 42^{\mathrm{G} 12 \mathrm{~V}}$ at $24 \mathrm{~h}$ after the transfection (data not shown). This ratio is almost comparable to that reported by Dutartre et al. (1996) using the stably transfected cells. These results suggest that the forced expression of the activated RhoD induces multinucleation in the cultured cells by preventing cytokinesis as has been postulated for $\mathrm{Cdc} 42$.

\section{Interference with cleavage and induction of multinucleation in Xenopus embryos by RhoD}

To confirm the postulation that the activated RhoD induces multinucleation by preventing cytokinesis, we microinjected the recombinant $\mathrm{RhoD}^{\mathrm{G} 26 \mathrm{~V}}$ or RhoD ${ }^{\mathrm{T} 31 \mathrm{~K}}$ protein into one blastomere of Xenopus laevis embryo at the two-cell stage. A cell injected only with the injection buffer cleaved normally (Figure 5Aa). The RhoD ${ }^{\mathrm{G} 26 \mathrm{~V}}$-injected cell, however, usually cleaved only once and ceased cleavage after that, whereas the opposite uninjected blastomere cleaved normally (Figure 5Ab). This injection consequently gave rise to hemiblastulation. Occurrence of one cleavage after the injection seems to be ascribable to a short period between the first and the second cleavage ( $\sim 30 \mathrm{~min})$ and a time lag between the injection and activation of the protein by the C-terminal modifications including isoprenylation (Glomset and Farnsworth, 1994) or accession of the modified RhoD to its target proteins. Microinjection of c-Mos RNA (Sagata et al., 1989), the anti-XAC antibody, or excess amounts of the constitutively active XAC protein (Abe et al., 1996) to one blastomere of the two-cell stage embryo similarly cleaved only once or a few times and generates hemiblastula. RhoD ${ }^{\mathrm{T} 31 \mathrm{~K}}$-injected cell cleaved normally and was indistinguishable from the uninjected embryo (Figure 5Ac).

To examine whether nuclear division took place or not in the $\mathrm{RhoD}^{\mathrm{G} 26 \mathrm{~V}}$-injected blastomere, paraffinembedded sections of the embryo was stained with bisbenzimide H33258. Two or three nuclei were detected in each section of the uncleaved blastomere (Figure 5Ba). Thus, the RhoD ${ }^{\mathrm{G} 26 \mathrm{~V}}$-injected cell became multinucleated. Mabuchi et al. (1993) have shown that 

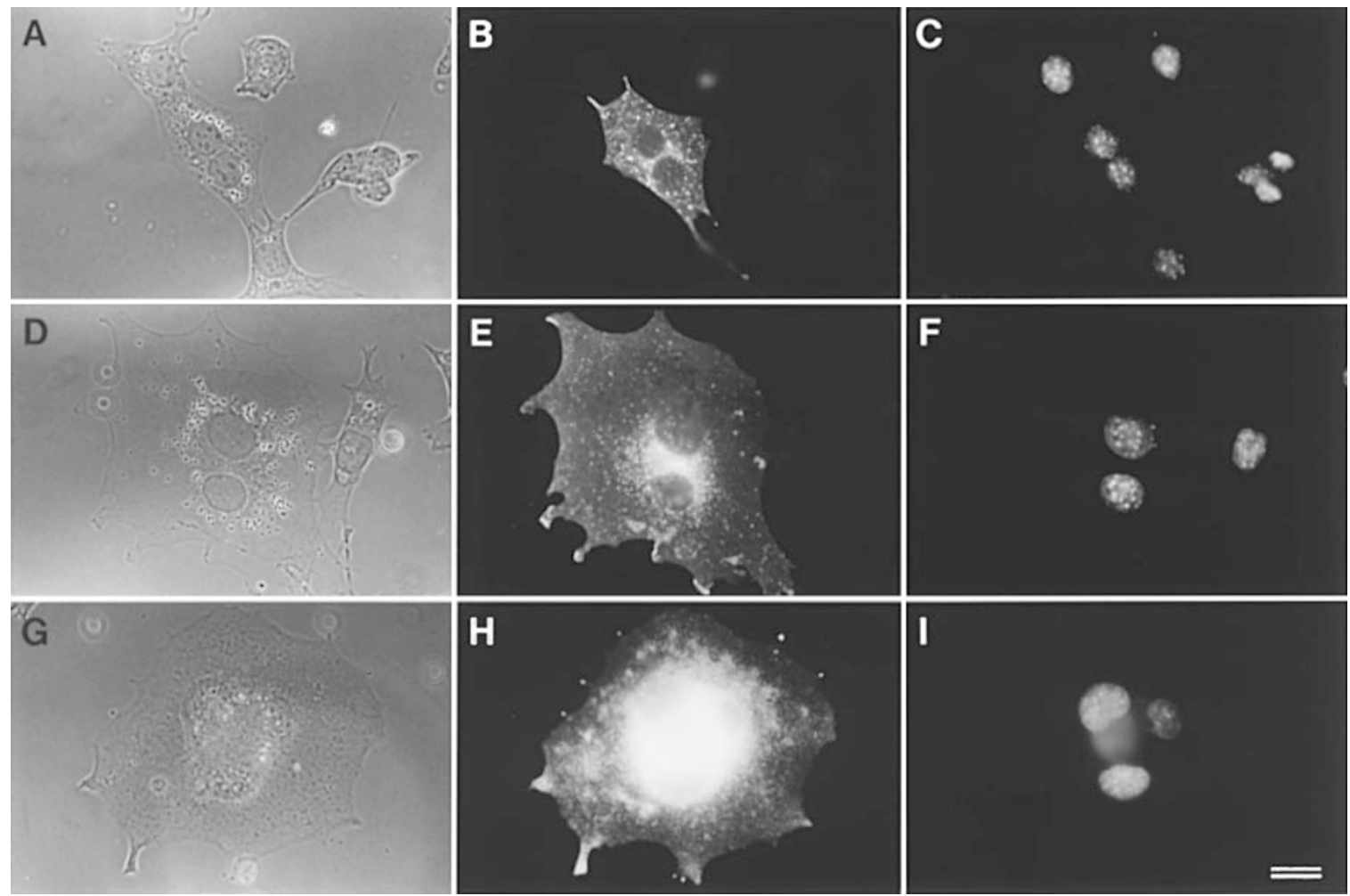

Figure 4 Induction of multinucleation in cultured cells by the activated RhoD. (a-c) A binucleated Balb/3T3 cell generated by the transfection of Myc-tagged RhoD ${ }^{\mathrm{G} 26 \mathrm{~V}}$ cDNA. (d - f) A binucleated $10 \mathrm{~T} 1 / 2$ cell generated by the expression of Myc- $\mathrm{RhoD}^{\mathrm{G} 26 \mathrm{~V}}$. $(\mathbf{g}-$ h) A tetranucleated N1E-115 cell generated by the expression of Myc-RhoD ${ }^{\mathrm{G} 26 \mathrm{~V}}$. Phase-contrast micrographs (a, d and $\mathbf{g}$ ), corresponding fluorescent micrographs detecting $\mathrm{RhoD}^{\mathrm{G} 26 \mathrm{~V}}$-expressing cells by staining with Myc1-9E10 (b, e and $\mathbf{h}$ ), and those detecting nuclei by staining with bisbenzimide H33258 (c, f and i). The cells were fixed $24 \mathrm{~h}$ after the transfection. Scale bar, $20 \mu \mathrm{m}$

Table 2 Ratio of multinucleation in $\mathrm{RhoD}^{\mathrm{G} 26 \mathrm{~V}}$-expressing

\begin{tabular}{llcrl}
\hline \multirow{3}{*}{ Cell line } & Transfected cDNA & \multicolumn{4}{c}{ Number of } & nuclei in & a cell $(\%)$ \\
Balb/3T3 & None (pCMVmyc) & 100 & 0 & Three \\
& RhoD $^{\mathrm{G} 26 \mathrm{~V}}$ & 90.9 & 8.5 & 0 \\
$\mathrm{C} 3 \mathrm{H} / 10 \mathrm{~T} 1 / 2$ & None (pCMVmyc) & 94.4 & 5.6 & 0 \\
& RhoD $^{\mathrm{G} 26 \mathrm{~V}}$ & 86.6 & 12.3 & 1.1 \\
\hline
\end{tabular}

$\mathrm{Balb} / 3 \mathrm{~T} 3$ and $10 \mathrm{~T} 1 / 2$ fibroblasts were transfected with the vacant pCMVmyc vector (none) or the vector harboring $\mathrm{RhoD}^{\mathrm{G} 26 \mathrm{~V}} \mathrm{cDNA}$. The cells were fixed $24 \mathrm{~h}$ after the transfection and doubly stained with Myc1-9E10 and H33258. More than 200 transfected cells in each transfection were examined to count the number of the nuclei

microinjection of $\mathrm{C} 3$ exoenzyme into sand dollar eggs induce multinucleation by preventing cytokinesis but not nuclear division. To compare the effects of $\mathrm{RhoD}^{\mathrm{G} 26 \mathrm{~V}}$ and $\mathrm{C} 3$ exoenzyme, each of these proteins was injected into Xenopus fertilized eggs before cleavage. The eggs injected with each protein cleaved only once and arrested cleavage after that. Because Xenopus embryos are opaque and thus the nuclei in intact whole embryos cannot be observed by microscopy, they were squashed after the staining with H33258 to count the total number of the nuclei. Both the $\mathrm{RhoD}^{\mathrm{G} 26 \mathrm{~V}}$-injected embryo and the $\mathrm{C} 3$ exoenzymeinjected embryo contained about 32 nuclei at the time corresponding to stage 6 of control embryo (Figure $5 \mathrm{Bb}$ and $\mathrm{c})$. Taken together, these results imply that the
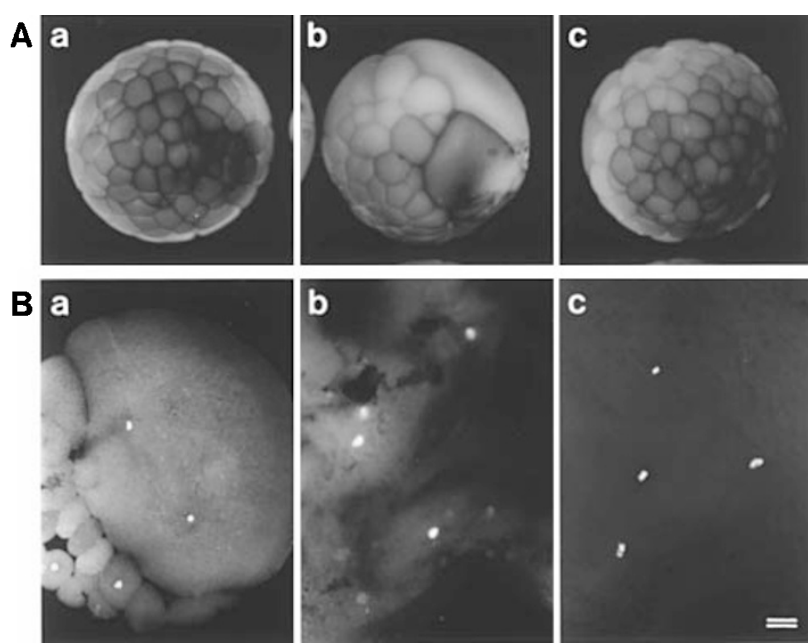

Figure 5 Interference with cleavage and induction of multinucleation in Xenopus embryos by the activated RhoD. (A) Hindrance to cleavage by microinjected $\mathrm{RhoD}^{\mathrm{G} 26 \mathrm{~V}}$. One blastomere of the two cell stage embryo was microinjected with the injection buffer as a control (a) and with the recombinant $\mathrm{RhoD}^{\mathrm{G} 26 \mathrm{~V}}$ (b) or $\mathrm{RhoD}^{\mathrm{T} 31 \mathrm{~K}}$ (c) protein. The embryos were fixed at stage 6-7 and viewed from the animal poles. (B) Induction of multinucleation by microinjected $\mathrm{RhoD}^{\mathrm{G} 2 \mathrm{~V}}$. (a) The embryo was injected with RhoD $\mathrm{D}^{\mathrm{G} 2 \mathrm{~V}}$ and fixed as above. A paraffin-embedded section was stained with $\mathrm{H} 33258$ to detect the nuclei. (b and c). The fertilized eggs were injected with $\mathrm{RhoD}^{\mathrm{G} 26 \mathrm{~V}}$ (b) or $\mathrm{C} 3$ exoenzyme (c) and fixed at the time corresponding to stage 6 of control embryo. The squashed embryos were stained with H33258. Only one microscopic field, which usually contains $1-$ 6 nuclei, is shown for each embryo. Scale bar, $100 \mu \mathrm{m}$ 
activated RhoD as well as C3 exoenzyme interferes with cytokinesis of the blastomeres without affecting nuclear division and that consequently the protein induces multinucleation in the blastomeres and in the cultured cells as well.

\section{Antagonistic effects of RhoD to RhoA action}

The above effects of RhoD appeared to be antagonistic to those of RhoA. To assess this possibility, constitutively activated $\mathrm{RhoA}^{\mathrm{G} 14 \mathrm{~V}}$, RhoD ${ }^{\mathrm{G} 26 \mathrm{~V}}$, or both the cDNAs were transfected to $10 \mathrm{~T} 1 / 2$ cells. The stress fibers were enhanced by the expression of hemagglutinin (HA)-tagged Rho $\mathrm{A}^{\mathrm{G} 14 \mathrm{~V}}$ in as much as $93 \%$ of the expressing cells (Figure 6a and b, Table 3). When $\mathrm{HA}-\mathrm{RhoA}^{\mathrm{G} 14 \mathrm{~V}}$ and $\mathrm{Myc}-\mathrm{RhoD}^{\mathrm{G} 26 \mathrm{~V}}$ ) cDNAs were cotransfected, the ratio of cells containing the enhanced stress fibers decreased to $80 \%$ (Figure $6 \mathrm{c}-$ e, Table 3). Thus, RhoD interferes at least in some of the cells with the stress fiber formation induced by RhoA.

The interference with the stress fiber formation only in a subset of the cotransfected cells might be due to the dual expression of the constitutively active RhoA $^{\mathrm{G} 14 \mathrm{~V}}$ and RhoD ${ }^{\mathrm{G} 26 \mathrm{~V}}$. Therefore, we next transfected only $\mathrm{Myc}-\mathrm{RhoD}^{\mathrm{G} 26 \mathrm{~V}} \mathrm{cDNA}$ to $10 \mathrm{~T} 1 / 2$ cells and then stimulated the cells with LPA to activate endogenous RhoA. More than $70 \%$ of the RhoD ${ }^{\mathrm{G} 26 \mathrm{~V}}$ expressing cells contained diminished stress fibers, whereas the unexpressing cells contained the stress fibers enhanced by the LPA treatment (Figure 6f and g). These results indicate that RhoD has an antagonistic effect to RhoA at least in the stress fiber formation.

Table 3 Interference of RhoD with RhoA-induced stress fiber formation

\begin{tabular}{lccc}
\hline \multicolumn{3}{c}{$\begin{array}{c}\text { Enhancement of stress } \\
\text { fibers }(\%)\end{array}$} \\
Transfected cDNA & $(+)$ & $(-)$ & Cell numbers counted \\
\hline $\mathrm{RhoA}^{\mathrm{G} 14 \mathrm{~V}}$ & 93.1 & 6.9 & 116 \\
$\mathrm{RhoA}^{\mathrm{G} 14 \mathrm{~V}}+\mathrm{RhoD}^{\mathrm{G} 26 \mathrm{~V}}$ & 80.9 & 19.1 & 139 \\
RhoD $^{\mathrm{G} 26 \mathrm{~V}}$ & 0 & 100 & 123 \\
\hline
\end{tabular}

10T1/2 cells were either singly transfected with $\mathrm{HA}-\mathrm{RhoA}^{\mathrm{G} 14 \mathrm{~V}}$ or $\mathrm{Myc}-\mathrm{RhoD}^{\mathrm{G} 26 \mathrm{~V}}$ cDNA or cotransfected with both the cDNAs. $\mathrm{HA}-\mathrm{RhoA}^{\mathrm{G} 14 \mathrm{~V}}$ - and $\mathrm{Myc}-\mathrm{RhoD}^{\mathrm{G} 26 \mathrm{~V}}$-expressing cells were detected by anti-HA-tag antibody and Myc1-9E10 staining, respectively. Stress fibers were detected by the staining with coumarin-phallacidin. The expressing cells with $(+)$ or without $(-)$ enhancement of the stress fibers were counted
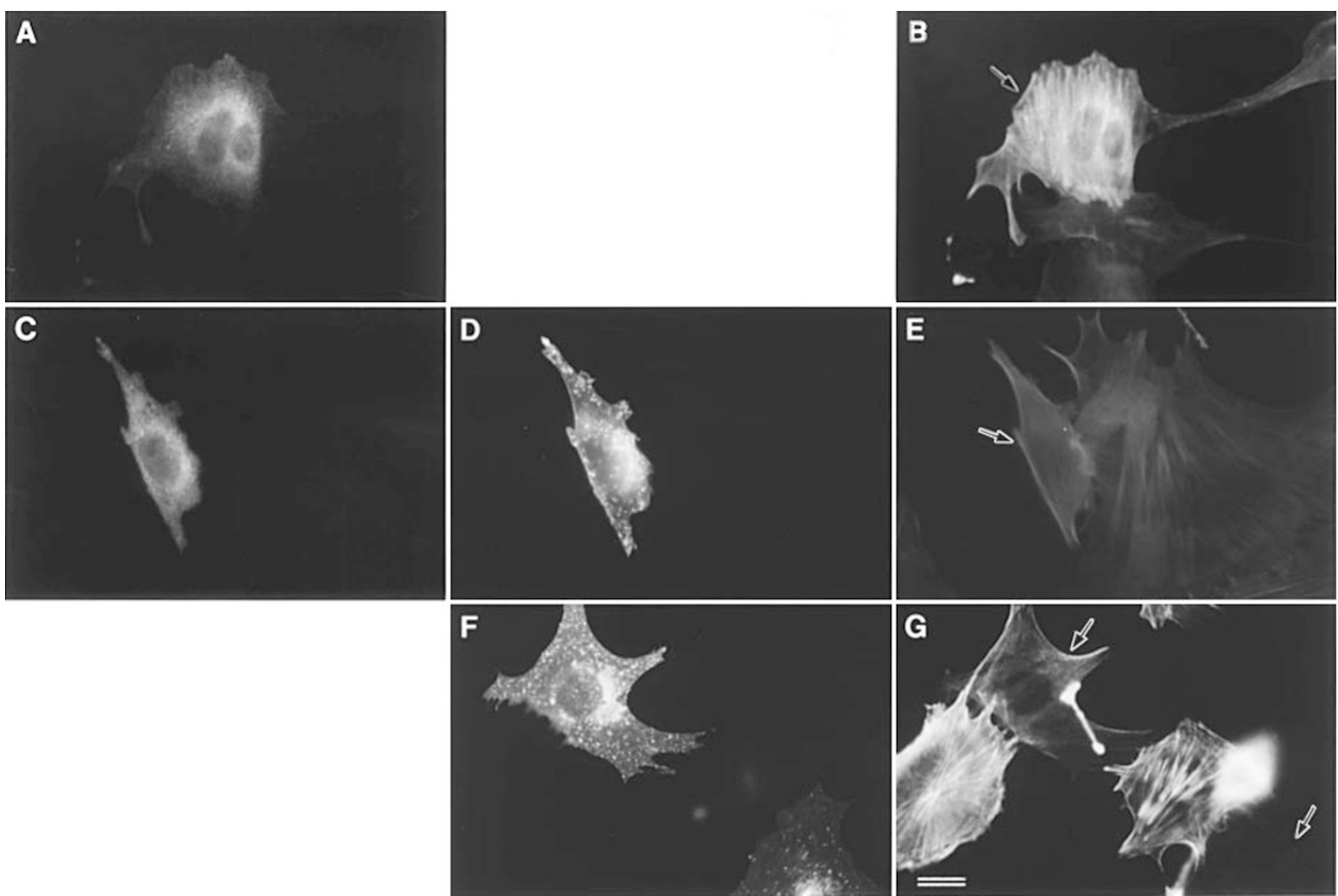

Figure 6 Antagonistic effects of RhoD to RhoA action inducing the stress fiber formation in 10T1/2 cells. (a and b) Cells transfected with HA-RhoA ${ }^{\mathrm{G} 14 \mathrm{~V}}$ cDNA, $24 \mathrm{~h}$ after the transfection. Stress fibers were enhanced in the RhoA ${ }^{\mathrm{G} 14 \mathrm{~V}}$-expressing cell (b, arrow). (c-e) Cells cotransfected with $\mathrm{HA}-\mathrm{RhoA}^{\mathrm{G} 14 \mathrm{~V}}$ and Myc-RhoD ${ }^{\mathrm{G} 26 \mathrm{~V}} \mathrm{cDMAs}, 24 \mathrm{~h}$ after the transfection. RhoA ${ }^{\mathrm{G} 14 \mathrm{~V}}$ induced enhancement of the stress fibers was suppressed by the coexpression of $\mathrm{RhoD}^{\mathrm{G} 26 \mathrm{~V}}$ (e, arrow). (f and $\mathbf{g}$ ) Cells transfected with Myc-RhoD ${ }^{\mathrm{G} 26 \mathrm{~V}}$ cDNA and stimulated with LPA. Twenty-four hours after the transfection, the cells were treated with $200 \mathrm{ng} /$ $\mathrm{ml}$ LPA for $10 \mathrm{~min}$. RhoD ${ }^{\mathrm{G} 26 \mathrm{~V}}$-expressing cells (arrows) contained diminished stress fibers, whereas unexpressing cells contained enhanced stress fibers (g). HA-RhoA ${ }^{\mathrm{G} 14 \mathrm{~V}}$-expressing cells were detected by anti-HA-tag antibody staining (a and c). Myc$\mathrm{RhoD}^{\mathrm{G} 26 \mathrm{~V}}$-expressing cells were detected by Mcyl-9E10 staining (d and f f). Actin filaments were detected by the staining with coumarin-phallacidin (blue fluorescence) (b and e) or with rhodamine-phalloidin (g). Scale bar, $20 \mu \mathrm{m}$ 
The above results urged us to determine how RhoD interferes with the effect of RhoA. One possible mechanism is that RhoD binds to effectors of RhoA to sequester them away from RhoA. The Rhoassociated kinase isozymes, Rho-kinase/ROCK-II/ $\mathrm{ROK} \alpha$ and $\mathrm{ROCK}-\mathrm{I} / \mathrm{ROK} \beta$, are the effector proteins of RhoA mediating the assembly of the stress fibers and focal adhesions (Leung et al., 1996; Amano et al., 1997; Ishizaki et al., 1997). To examine whether RhoD affects Rho-kinase, interaction of $\mathrm{RhoD}^{\mathrm{G} 26 \mathrm{~V}}$ and $\mathrm{RhoA}^{\mathrm{G} 14 \mathrm{~V}}$ with each domain of Rho-kinase (Amano et al., 1997) was analysed by ligand overlay assay. RhoA ${ }^{\mathrm{G} 14 \mathrm{~V}}$ strongly bound to the Rho-binding domain, whereas RhoD ${ }^{\mathrm{G} 26 \mathrm{~V}}$ did not bind to any domains of Rho-kinase in this assay (Figure 7). Consequently, RhoD is likely to antagonize RhoA action inducing the stress fibers through a way other than direct prevention of Rho-kinase.

\section{Discussion}

The amino acid sequence within the core effector domain and the putative extended effector domain of RhoD is distinct from those of the other Rho family members. As has been expected from its sequence divergence, RhoD exerted unique cellular effects different from those of the known Rho family proteins. Microinjection of the constitutively active RhoD ${ }^{\mathrm{G} 26 \mathrm{~V}}$ protein into fibroblasts and transfection of its cDNA to fibroblasts resulted in disassembly of the actin stress fibers and associated focal adhesions as has been reported by Murphy et al. (1996). RhoA mediates the formation of the stress fibers and focal adhesions in cultured cells stimulated by extracellular signaling molecules such as LPA (Ridley and Hall, 1992). Introduction of the activated $\mathrm{RhoA}^{\mathrm{G} 14 \mathrm{~V}}$ protein in cultured cells by microinjection or transfection brings about the same cytoskeletal changes (Ridley and Hall, 1992; Amano et al., 1997; Uehara et al., 1997; Sahai et

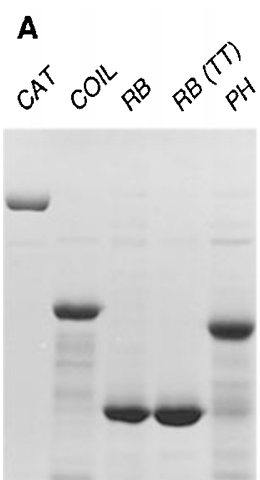

SDS-PAGE
$\mathbf{B}$

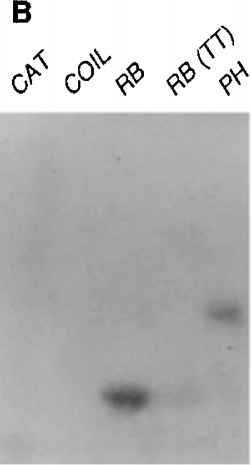

RhoA G14V
C
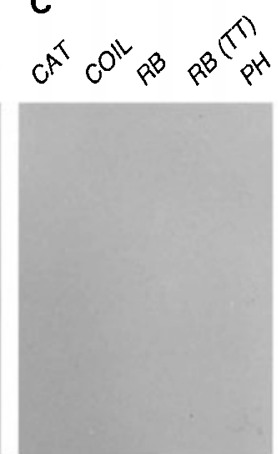

RhoD G26V
Figure 7 Ligand overlay assay for interaction between RhoA $^{\mathrm{G} 14 \mathrm{~V}}$ or RhoD ${ }^{\mathrm{G} 26 \mathrm{~V}}$ and Rho-kinase. (a) SDS-PAGE of recombinant proteins of each domain of Rho-kinase. CAT, catalytic domain; COIL, coiled-coil domain; RB, Rho-binding domain; RB (TT), Rho-binding domain with loss-of-function mutation; $\mathrm{PH}, \mathrm{PH}$ domain. (b) Ligand overlay assay for interaction between $\mathrm{RhoA}^{\mathrm{G} 14 \mathrm{~V}}$ and each domain of Rho-kinase. RhoA ${ }^{\mathrm{G} 14 \mathrm{~V}}$ strongly bound to RB domain. (c) Ligand overlay assay for interaction between $\operatorname{RhoD}^{\mathrm{G} 26 \mathrm{~V}}$ and each domain of Rho-kinase. No interaction was detected al., 1998). Cotransfection of $\mathrm{RhoA}^{\mathrm{G} 14 \mathrm{~V}}$ and $\mathrm{RhoD}^{\mathrm{G} 26 \mathrm{~V}}$ cDNAs brought about interference with enhancement of the stress fibers induced by $\mathrm{RhoA}^{\mathrm{G} 14 \mathrm{~V}}$ in a subset of the coexpressing cells. Moreover, transfection of $\mathrm{RhoD}^{\mathrm{G} 26 \mathrm{~V}}$ cDNA followed by LPA treatment not only prevented LPA-induced enhancement of the stress fibers but also diminished preexisting stress fibers. These results imply that RhoD has an antagonistic effect to RhoA at least in the stress fiber formation.

Transfection of RhoD $^{\mathrm{G} 26 \mathrm{~V}}$ cDNA to fibroblasts resulted in retardation of cell migration as detected by phagokinetic track analysis. Since it has been postulated that actin-associated structures are required for cell migration (Lauffenburger and Horwitz, 1996; Mitchison and Cramer, 1996), the alterations in cytoskeletons and cell adhesions including the stress fibers and focal adhesions by the activated RhoD may lead to the interference with cell migration. Inactivation of RhoA and related proteins by $\mathrm{C} 3$ exoenzyme or Rho GDI causes inhibition of cell migration (Takaishi et al., 1993,1994). These findings corroborate the above notion. Cells transformed with the activated RhoA or Racl as well as with the oncogenic guanine nucleotide exchange factors (GEFs) (Dbl, Ost, Tiam-1, and Vav) for Rho family members exhibit invasive and metastatic potential either in vivo or in vitro (Habets et al., 1994; Michiels et al., 1995; del Peso et al., 1997). RhoA and Racl are therefore likely to play important roles in aquisition of invasive and metastatic properties of tumor cells. In this context, RhoD might be applicable to prevent invasive and metastatic potential of the transformed cells.

Multinucleation was induced in several cell types including fibroblasts and neuroblastoma cells transfected with RhoD ${ }^{\mathrm{G} 26 \mathrm{~V}}$ cDNA. Induced expression of the constitutively active $\mathrm{Cdc} 42^{\mathrm{G} 12 \mathrm{~V}}$ in $\mathrm{HeLa}$ cells also results in multinucleated cells (Dutartre et al., 1996). The ratio of multinucleated cells induced by the transfection of the RhoD cDNA was almost comparable to that in the Cdc42-expressing cells. Multinucleated cells are also generated by forced expression of the oncogenic forms of Vav, Dbl, and Tiam-1 (Katzav et al., 1989; Ron et al., 1991; Habets et al., 1994), which exhibit GEF activity for Cdc42 (Hart et al., 1991; Michiels et al., 1995; Han et al., 1997). Because Cdc42 is implicated in the reorganization of actin cytoskeleton (Kozma et al., 1995; Nobes and Hall, 1995; Dutartre et al., 1996), formation of the contractile rings or some cytoskeletal structures required for cytokinesis may be abrogated by deregulated expression of Cdc42. Similarly, overexpression of the activated RhoD is likely to prevent cytokinesis by suppressing the formation of these cytoskeletal structures. The prevention of cytokinesis without affecting nuclear division seems to result in the formation of multinucleated cells. Recently, citron kinase, an effector protein of RhoA, has been shown to be involved in cytokinesis (Madaule et al., 1998) Transfection of cDNAs encoding the truncation mutants of citron kinase results in a failure in cytokinesis to generate multinucleated cells. This finding also supports the possibility that deregulated expression of $\mathrm{RhoD}^{\mathrm{G} 26 \mathrm{~V}}$ gives rise to multinucleated cells through interfering with RhoA action. Although the RhoD ${ }^{\mathrm{G} 26 \mathrm{~V}}$-expressing cells as well as the $\mathrm{Cdc} 42^{\mathrm{G} 12 \mathrm{~V}}$ expressing cells contained two or three nuclei, they 
rarely contained more than four nuclei even after long cultivation. This might be due to intrinsic restrictions of cells to accommodate too many nuclei such as limited cytoplasmic volume without cytokinesis.

Microinjection of $\mathrm{RhoD}^{\mathrm{G} 26 \mathrm{~V}}$ protein into the Xenopus eggs and embryos demonstrated the above possibility that the multinucleation in $\mathrm{RhoD}^{\mathrm{G} 26 \mathrm{~V}}$-expressing cells is induced by the prevention of cytokinesis without affecting nuclear division. When C3 exoenzyme or Rho GDI is injected into Xenopus embryos (Kishi et al., 1993; Drechsel et al., 1997) or sand dollar eggs (Mabuchi et al., 1993), formation of the contractile rings is impaired. Inhibition of RhoA by these proteins results in the interference with cytoplasmic cleavage but not with nuclear division and consequently multinucleation is induced (Kishi et al., 1993; Mabuchi et al., 1993). These findings indicate that the effects of the activated RhoD on cytokinesis are similar to those of the inhibitors of RhoA activity and further suggest that RhoD antagonizes RhoA also in cytokinesis. Exerting the effects of RhoD in Xenopus embryos imply that its target proteins and possibly a protein homologous to mammalian RhoD are present in Xenopus embryos.

According to the previous report (Murphy et al., 1996), thin long processes containing actin filaments were commonly $(70 \%)$ formed in cells exogenously expressing wild-type RhoD or RhoD ${ }^{\mathrm{G} 26 \mathrm{~V}}$. In the present study, however, such processes were not definitely detected in the microinjected cells or in the transfected cells compared with uninjected or untransfected cells. One possible explanation for the discrepancy between their results and ours might stem from the differences in the expression systems or in the cells used. Indeed, the activated $\mathrm{RhoA} \mathrm{A}^{\mathrm{G} 14 \mathrm{~V}}$ did not stimulate the stress fiber formation in their T7 vaccinia virus system (Murphy et al., 1996), whereas we constantly observed that $\mathrm{RhoA}^{\mathrm{G} 14 \mathrm{~V}}$ stimulates the formation of stress fibers and focal adhesions in both microinjection and transfection experiments (see Figure 6b) as reported by many investigators (Ridley and Hall, 1992; Amano et al., 1997; Uehara et al., 1997; Sahai et al., 1998).

Several effector proteins of RhoA have been identified (Narumiya, 1996; Narumiya et al., 1997; Tapon and Hall, 1997; Van Aelst and D'SouzaSchorey, 1997). The Rho-associated kinase isozymes, Rho-kinase/ROCK-II/ROK $\alpha$ and ROCK-I/ROK $\beta$, mediate the assembly of the stress fibers and focal adhesions (Leung et al., 1996; Amano et al., 1997; Ishizaki et al., 1997), presumably by inhibitory phosphorylation of myosin phosphatase subunit and direct phosphorylation of myosin light chain leading to actin-myosin interaction (Kimura et al., 1996; Amano et al., 1996; Chihara et al., 1997) and by phosphorylation of the Na-H exchanger NHE1 leading to increased binding of integrin to extracellular matrix proteins (Tominaga et al., 1998). Another effector protein mDia is involved in actin polymerization by recruiting profilin (Watanabe et al., 1997). Citron kinase is likely to play essential roles in RhoA-mediated cytokinesis (Madaule et al., 1998). To address how RhoD interferes with the effects of RhoA, we assessed the possibility that RhoD sequester Rho-kinase from RhoA by binding to the kinase. Although RhoD did not appreciably interact with any domains of Rhokinase, the interaction between RhoD and the other effector proteins remains to be examined. Alternatively, either direct sequestration of RhoA by RhoD or regulation by RhoD of upstream regulators for RhoA, i.e., inhibition of GEFs or constitutive activation of Rho GDI or GTPase-activating proteins (GAPs), might be plausible for simultaneous interference with multiple effects of RhoA.

Recently identified Rho family proteins, Rnd1 and Rnd3/RhoE, which may exist as intrinsically active forms, also disassemble the stress fibers and focal adhesions and prevent the formation of these structures induced by LPA (Nobes et al., 1998). These proteins and RhoD, however, may antagonize RhoA action through different ways because the core effector domains of Rnd1 and Rnd3 are identical to that of RhoA and distinct from that of RhoD. In any case, RhoD and Rnd might serve as novel types of regulators for RhoA and other Rho family proteins.

\section{Materials and methods}

\section{Expression and purification of recombinant proteins}

Point mutations to generate the constitutively active form of $\mathrm{RhoD}^{\mathrm{G} 26 \mathrm{~V}}$ and the dominant negative form of $\mathrm{RhoD}^{\mathrm{T} 31 \mathrm{~K}}$ were introduced in the cDNA with Transformer sitedirected mutagenesis kit (Clontech Laboratories, Inc.). Coding sequences of the wild-type and the mutated RhoD were fused in frame to glutathione $S$-transferase (GST) in pGEX-2T vector (Pharmacia Biotech). These recombinant fusion proteins were expressed in E. coli strain XL1-Blue and affinity-purifed with glutathione-Sepharose (Pharmacia Biotech) as described (Matsumoto et al., 1997). GST moiety was removed from the fusion proteins by digesting with $10 \mathrm{U} / \mathrm{ml}$ bovine thrombin (Sigma) (Matsumoto et al., 1997).

\section{Microinjection into cultured cells}

Swiss 3T3 fibroblasts (Todaro and Green, 1963) were grown on glass coverslips in Dulbecco's modified Eagle's (DME) medium containing 10\% fetal calf serum (growth medium). Serum-starved subconfluent cells were prepared by culturing the cells for $48 \mathrm{~h}$ in DME medium containing $0.2 \% \mathrm{NaHCO}_{3}$ (Kozma et al., 1995). The recombinant proteins of the constitutively active and the dominant negative RhoD were microinjected into the cells as described previously (Matsumoto et al., 1997). Fluorescein-conjugated dextran (Molecular Probes, Inc.) at a final concentration of $0.5 \mathrm{mg} / \mathrm{ml}$ was coinjected with the proteins to allow identification of injected cells. The cells were fixed and permeabilized and actin filaments were detected by staining with rhodamine-phalloidin (Molecular Probes, Inc.) as described (Endo et al., 1996). The specimens were observed with a Zeiss Axioskop microscope equipped with phase-contrast and epifluorescence optics.

\section{Microinjection into Xenopus embryos and sectioning of the} embryos

About $10 \mathrm{nl}$ of the recombinant $\mathrm{RhoD}^{\mathrm{G} 26 \mathrm{~V}}$ or $\mathrm{RhoD}^{\mathrm{T} 31 \mathrm{~K}}$ protein at $3 \mathrm{mg} / \mathrm{ml}$ in the injection buffer $(80 \mathrm{mM} \mathrm{NaCl}$, $4 \mathrm{mM} \mathrm{MgCl}_{2}, 4 \mathrm{mM}$ HEPES- $\mathrm{NaOH}, \mathrm{pH} 7.0$, and $0.1 \mathrm{~mm}$ dithiothreitol) were microinjected into one blastomere of Xenopus laevis embryos at the 2-cell stage. They were microinjected with glass capillary needles by using a micromanipulator (Narishige MO-102R) and a microinjector (Shimadzu CIJ-1). The embryos were fixed as described (Abe et al., 1996) at appropriate stages after the injection. 
They were observed with a Zeiss 2000-C dissection microscope equipped with overhead illumination. The fixed embryos in $100 \%$ ethanol were embedded in paraffin and 5-6 $\mu \mathrm{m}$-thick sections were prepared. They were mounted on ovalbumin-coated slide glasses and stained with $1 \mu \mathrm{g} / \mathrm{ml}$ bisbenzimide $\mathrm{H} 33258$ (Hoechst 33258). C3 exoenzyme expression plasmid pET-3a/C3 was presented by $\mathrm{Dr} \mathrm{S}$ Narumiya, and the C3 exoenzyme was prepared according to Morii and Narumiya (1995). The recombinant $\mathrm{RhoD}^{\mathrm{G} 26 \mathrm{~V}}$ or $\mathrm{C} 3$ exoenzyme was injected into Xenopus fertilized eggs. At the time corresponding to stage 6 of control embryo, the injected embryos were pricked with a tungsten needle and fixed with methanol. They were mounted on slide glasses, stained with H33258, and squashed with coverslips. The specimens were observed with the Zeiss Axioskop microscope with a $10 \times$ PlanNeofluar lens as stated above.

\section{Epitope tagging and transfection}

The cDNAs containing the entire coding region of the wild-type and the mutated RhoD were fused in frame to the N-terminal Myc-tag in pCMVmyc vector (Matsumoto et al., 1997). RhoA ${ }^{\mathrm{G} 14 \mathrm{~V}}$ cDNA was subcloned in pEF-BOSHA3 vector (Amano et al., 1997). Cdc42 ${ }^{\mathrm{G} 12 \mathrm{~V}}$ cDNA subcloned in pEF-BOS-myc vector was presented by Dr Y Takai. The mouse C3H/10T1/2 fibroblasts (Reznikoff et al., 1973), mouse Balb/3T3 fibroblasts (Aaronson and Todaro, 1968), and mouse N1E-115 neuroblastoma cells (Amano et al., 1972) were grown on glass coverslips in the growth medium. They were transfected with these plasmids by the calcium phosphate-mediated method as described (Endo et al., 1996). The transiently transfected cells were processed for immunofluorescence microscopy (Endo and Nadal-Ginard, 1998). The fixed and permeabilized cells were incubated with the mAb Myc1-9E10 recognizing the Myc-tag (Evan et al., 1985) (American Type Culture Collection) or with anti-HA-tag rabbit IgG (MBL) and then with fluorescein isothiocyanate (FITC)-conjugated goat anti-mouse or anti-rabbit IgG (affinity-purified, Cappel Laboratories). To detect actin filaments, rhodamine-phalloidin or coumarin-phallacidin (Molecular Probes, Inc.) was included in the secondary antibody. To examine the focal adhesions, affinity-purified anti-chicken gizzard vinculin (Endo and Masaki, 1982; Fukami et al., 1994) was included in the primary antibody. To observe the nuclei, cells were further stained with bisbenzimide H33258. When 10T1/2 cells were cotransfected with
pCMVmycRhoD and pEF-BOS-HA3/RhoA, they were incubated with Myc1-9E10 plus anti-HA-tag and then with FITC-anti-mouse IgG plus rhodamine-anti-rabbit IgG and coumarin-phallacidin (emitting blue fluorescence through UV filters). The specimens were observed with Zeiss Axioskop microscope as stated above.

\section{Phagokinetic tracks}

Gold particles were prepared and glass coverslips were coated with the particles according to Albrecht-Buehler (1977). The mutated RhoD cDNAs in pCMVmyc vector were transfected to $10 \mathrm{~T} 1 / 2$ cells. Six hours after the glycerol shock, the cells were replated on the gold particle-coated coverslips. They were fixed $18 \mathrm{~h}$ after the replating and processed for immunofluorescent staining with Myc1-9E10. The specimens were observed by dark field microscopy and fluorescence microscopy.

\section{Ligand overlay assay}

Coiled-coil (COIL), Rho-binding (RB), loss-of-functionmutated Rho-binding (RB(TT)), and PH domains of Rhokinase were expressed as recombinant GST-fusion proteins in E. coli (Amano et al., 1997). GST-catalytic (CAT) domain was produced in Sf9 cells by the baculovirus system (Amano et al., 1997). These affinity-purified proteins were subjected to SDS-PAGE and transferred to Immobilon PVDF membrane (Millipore). They were probed with $\alpha{ }^{-32} \mathrm{P}$

GTP-labeled GST-RhoA ${ }^{\mathrm{G} 14 \mathrm{~V}}$ or GST-RhoD ${ }^{\mathrm{G} 26 \mathrm{~V}}$ according to Manser et al. (1995). Washed membrane was exposed to an X-ray film RX (Fuji).

\section{Acknowledgements}

We are grateful to Dr Shuh Narumiya for the generous gift of the C3 exoenzyme expression plasmid, to Dr Yoshimi Takai for the Cdc42 expression plasmid, and to Dr Takashi Obinata for permitting us to use laboratory facilities. This study was supported by research grants to $\mathrm{T}$ Endo from the Ministry of Education, Science, Sports, and Culture of Japan and from the Ministry of Health and Welfare of Japan for Nervous and Mental Disorders (8A-1). K Matsumoto is a Research Fellow of the Japan Society for the Promotion of Science.

\section{References}

Aaronson SA and Todaro GJ. (1968). J. Cell. Physiol., 72, $141-148$

Abe H, Obinata T, Minamide LS and Bamburg JR. (1996). $J$. Cell Biol., 132, $871-885$.

Albrecht-Buehler G. (1977). Cell, 11, 395-404.

Amano T, Richelson E and Nirenberg M. (1972). Proc. Natl. Acad. Sci. USA, 69, 258-263.

Amano M, Ito M, Kimura K, Fukata Y, Chihara K, Nakano T, Matsuura Y and Kaibuchi K. (1996). J. Biol. Chem., 271, 20246-20249.

Amano M, Chihara K, Kimura K, Fukata Y, Nakamura N, Matsuura Y and Kaibuchi K. (1997). Science, 275, 1308 1311.

Chihara K, Amano M, Nakamura N, Yano T, Shibata M, Tokui T, Ichikawa H, Ikebe R, Ikebe $\mathrm{M}$ and Kaibuchi K. (1997). J. Biol. Chem., 272, $25121-25127$.

del Peso L, Hernández-Alcoceba R, Embade N, Carnero A, Esteve P, Paje C and Lacal C. (1997). Oncogene, 15, $3047-$ 3057.

Drechsel DN, Hyman AA, Hall A and Glotzer M. (1997). Curr. Biol., 7, $12-23$.

Drivas GT, Shih A, Coutavas E, Rush MG and D'Eustachio P. (1990). Mol. Cell. Biol., 10, $1793-1798$.

Dutartre H, Davoust J, Gorvel J-P and Chavrier P. (1996). J. Cell Sci., 109, $367-377$.

Endo T and Masaki T. (1982). Biochem. Biophys. Res. Commun., 107, $1467-1474$.

Endo T and Nadal-Ginard B. (1998). J. Cell Sci., 111, $1081-$ 1093.

Endo T, Matsumoto K, Hama T, Ohtsuka Y, Katsura G and Obinata T. (1996). J. Biol. Chem., 271, $27855-27862$.

Evan GI, Lewis GK, Ramsay G and Bishop JM. (1985). Mol. Cell. Biol., 5, 3610-3616.

Foster R, Hu K-Q, Lu Y, Nolan KM, Thissen J and Settleman J. (1996). Mol. Cell. Biol., 16, 2689-2699.

Fukami K, Endo T, Imamura M and Takenawa T. (1994). J. Biol. Chem., 269, 1518-1522. 
Glomset JA and Farnsworth CC. (1994). Annu. Rev. Cell Biol., 10, 181-205.

Habets GGM, Scholtes EHM, Zuydgeest D, van der Kammen RA, Stam JC, Berns A and Collard JG. (1994). Cell, 77, 537-549.

Hall A. (1998). Science, 279, 509-514.

Han J, Das B, Wei W, van Aelst L, Mosteller RD, KhosraviFar R, Westwick JK, Der CJ and Broek D. (1997). Mol. Cell. Biol., 17, 1346-1353.

Hart MJ, Eva A, Evans T, Aaronson SA and Cerione RA. (1991). Nature, 354, 311-314.

Ishizaki T, Naito M, Fujisawa K, Maekawa M, Watanabe N, Saito Y and Narumiya S. (1997). FEBS Lett., 404, $118-$ 124.

Katzav S, Martin-Zenca D and Barbacid M. (1989). EMBO J., 8, 2283-2290

Kimura K, Ito M, Amano M, Chihara K, Fukata Y, Nakafuku M, Yamamori B, Feng J, Nakano T, Okawa K, Iwamatsu A and Kaibuchi K. (1996). Science, 273, $245-248$

Kishi K, Sasaki T, Kuroda S, Itoh T and Takai Y. (1993). J. Cell Biol., 120, $1187-1195$.

Kozma R, Ahmed S, Best A and Lim L. (1995). Mol. Cell. Biol., 15, $1942-1952$.

Lauffenburger DA and Horwitz AF. (1996). Cell, 84, $359-$ 369.

Leung T, Chen X-Q, Manser E and Lim L. (1996). Mol. Cell. Biol., 16, 5313-5327.

Mabuchi I, Hamaguchi Y, Fujimoto H, Morii N, Mishima M and Narumiya S. (1993). Zygote, 1, 325-331.

Madaule P, Eda M, Watanabe N, Fujisawa K, Matsuoka T, Bito H, Ishizaki T and Narumiya S. (1998). Nature, 394, $491-494$

Manser E, Leung T and Lim L. (1995). Methods Enzymol., 256, $130-139$.

Marks PW and Kwiatkowski DJ. (1996). Genomics, 38, 13 18.

Matsumoto K, Asano T and Endo T. (1997). Oncogene, 15, $2409-2417$.

Morii N and Narumiya S. (1995). Methods Enzymol., 256, $196-206$

Michiels F, Habets GGM, Stam JC, van der Kammen RA and Collard JG. (1995). Nature, 375, $338-340$.

Mitchison TJ and Cramer LP. (1996). Cell, 84, 371-379.

Moll J, Sansig G, Fattori E and van der Putten H. (1991). Oncogene, 6, 863-866.

Murphy C, Saffrich R, Grummt M, Gournier H, Rybin V, Rubino M, Auvinen P, Lütcke A, Parton RG and Zerial M. (1996). Nature, 384, 427-432.

Nakamura T, Asano M, Shindo-Okada N, Nishimura S and Monden Y. (1996). Biochem. Biophys. Res. Commun., 226, 688-694.
Narumiya S. (1996). J. Biochem., 120, 215-228.

Narumiya S, Ishizaki T and Watanabe N. (1997). FEBS Lett., 410, $68-72$.

Nishiyama T, Sasaki T, Takaishi K, Kato M, Yaku H, Araki K, Matsuura Y and Takai Y. (1994). Mol. Cell. Biol., 14, $2447-2456$

Nobes CD and Hall A. (1995). Cell, 81, 53-62.

Nobes CD, Lauritzen I, Mattei M-G, Paris S, Hall A and Chardin P. (1998). J. Cell Biol., 141, 187-197.

Reznikoff CA, Brankow DW and Heidelberger C. (1973). Cancer Res., 33, 3231-3238.

Ridley AJ and Hall A. (1992). Cell, 70, 389-399.

Ridley AJ, Paterson HF, Johnson CL, Diekmann D and Hall A. (1992). Cell, 70, 401-410.

Ron D, Zannini M, Lewis M, Wickner RB, Hunt LT, Graziani G, Tronick SR, Aaronson SA and Eva A. (1991). New Biol., 3, 372-379.

Sagata N, Watanabe N, Vande Woude GF and Ikawa Y. (1989). Nature, 342, 512-518.

Sahai E, Alberts AS and Treisman R. (1998). EMBO J., 17, $1350-1361$.

Segade F, Claudio E, Wrobel K, Ramos S and Lazo PS. (1995). J. Immunol., 154, 2384-2392.

Self AJ, Paterson HF and Hall A. (1993). Oncogene, 8, $655-$ 661.

Shirsat NV, Pignolo RJ, Kreider BL and Rovera G. (1990). Oncogene, 5, $769-772$.

Takaishi K, Kikuchi A, Kuroda S, Kotani K, Sasaki T and Takai Y. (1993). Mol. Cell. Biol., 13, $72-79$.

Takaishi K, Sasaki T, Kato M, Yamochi W, Kuroda S, Nakamura T, Takeichi M and Takai Y. (1994). Oncogene, 9, 273-279.

Tapon N and Hall A. (1997). Curr. Opin. Cell Biol., 9, 8692.

Todaro GJ and Green H. (1963). J. Cell Biol., 17, 299-313.

Tominaga T, Ishizaki T, Narumiya S and Barber DL. (1998). EMBO J., 17, $4712-4722$.

Uehara M, Ishizaki T, Satoh H, Ono T, Kawahara T, Morishita T, Tamakawa H, Yamagami K, Inui J, Maekawa M and Narumiya S. (1997). Nature, 389, 990994.

Van Aelst L and D'Souza-Schorey C. (1997). Genes Dev., 11, $2295-2322$.

Vincent S, Jeanteur P and Fort P. (1992). Mol. Cell. Biol., 12, $3138-3148$.

Watanabe N, Madaule P, Reid T, Ishizaki T, Watanabe G, Kakizuka A, Saito Y, Nakao K, Jockushu BM and Narumiya S. (1997). EMBO J., 16, 3044-3056.

Yeramian P, Chardin P, Madaule P and Tavitian A. (1987). Nucleic acids Res., 15, 1869. 